\title{
¿El estado opuesto al crecimiento económico?
}

Gilberto José Rafael Cárdenas Núñez

Resumen: El crecimiento económico del Perú es muy diferente al incremento del Producto Bruto interno. El reciente boom exportador y la mayor recaudación tributaria no están siendo aprovechadas por el gobierno para generar inversiones que constituyan una base productiva sostenible en el largo plazo que permitan mantener la dinámica productiva al término de esta expansión exportadora. La reforma del Estado, la formación de recursos humanos calificados y el plan estratégico se convierten en criterios centrales para la economía peruana en el periodo de la globalización contemporánea.

Palabras claves: Crecimiento, Estado, Producto, Globalización, Crisis 


\section{Gilberto José Rafael Cárdenas Núñez}

\section{Introducción}

Desde la crisis asiática de los años 1997 y 1998, la globalización contemporánea no había tenido otro reto que pusiera en jaque las teorías económicas de vigencia contemporánea. Keynes y su concepción que una recesión se resuelve con una intervención activa del Estado a través del gasto, encontraron en la crisis del petróleo de 1973 y 1974 el cuestionamiento central al intervencionismo público. Solow, Romer, Usawa y otros neoclásicos encontraron también en la crisis de 1997 - 1998 el cuestionamiento a la concepción de un libre mercado mundial como regulador de las transacciones internacionales que figuraban como motores de la expansión de la economía mundial. La acción del gobierno notteamericano de entonces, en coordinación con importantes inversionistas financieros fue indispensable para evitar una profundización de la crisis.

El crecimiento económico del Perú, medido por el PBI per cápita es mínimo debido a la evolución de la variable demográfica y al débil impulso de la producción tanto para el mercado interno como para la exportación.

\section{Cuadro $N^{\circ} 1$}

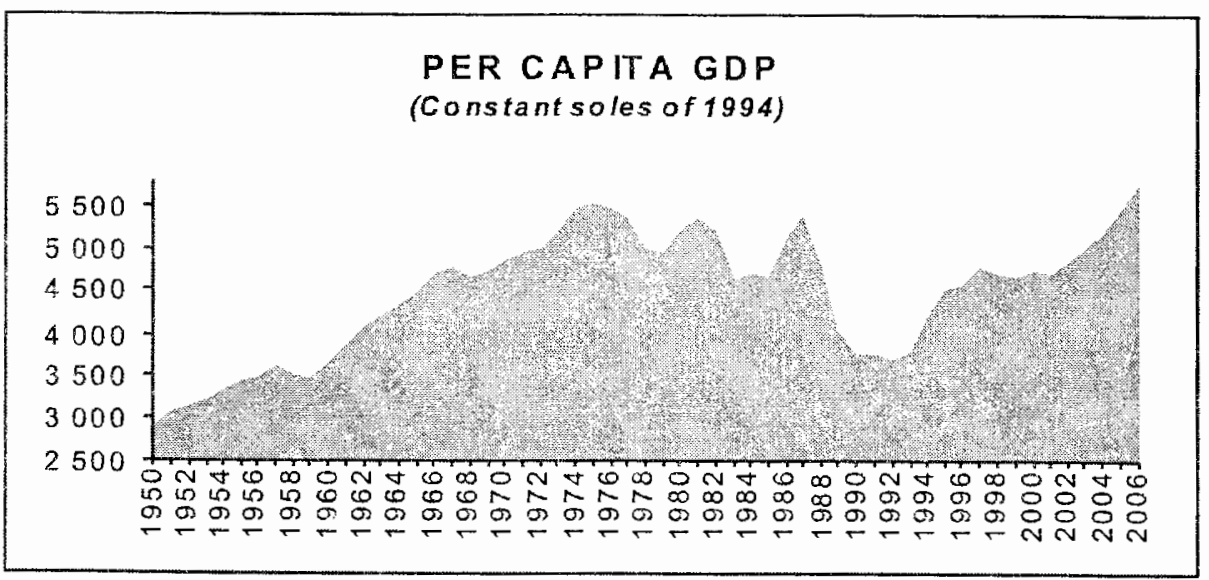

Fuente: Ministerio de Economia y Finanzas Exposición del Ministro Carraza 


\section{¿El estado opuesto al crecimiento económico?}

Para el año 2007 se espera que el PBI per cápita en valores corrientes supere los 4 mil dólares en el Perú, que en términos reales es también superior al valor máximo alcanzado en 1975 y en el año 2006, circunstancia que da entender que los 30 últimos años (tres décadas perdidas) podrían estar superándose eventualmente en términos promedios sin que necesariamente esto signifique una mejor redistribución del ingreso.

Es importante señalar que el PBI per cápita nominal para el 2007 en el Perú es de alrededor de US\$ 4000 (en términos reales es cerca de US\$2100) lo que significa en términos medios que la economía peruana esta en situación similar, según este indicador, a la del año 1975.

\section{2.- HACIA UNA SEGUNDA CRISIS DE LA GLOBALIZACIÓN CONTEMPORÁNEA}

Los últimos meses del 2007 fueron testigos de sucesivas bajas en los índices de la bolsa en los Estados Unidos: ${ }^{\mathrm{N}}$

"El crecimiento de Latinoamérica también se verá afectado por los 'relativamente bajos ritmos de inversión', según el estudio.

De acuerdo con el EIU, el año 2008 será 'menos propicio para el crecimiento' que el ejercicio que termina y en el que los mercados emergentes han tenido resultados 'excepcionales'.

Esos mercados se han beneficiado además de la gran liquidez de los mercados financieros derivada del fuerte crecimiento en petrodólares, de las intervenciones en divisas de los bancos centrales asiáticos y de los excedentes acumulados gracias a una política monetaria suave de EEUU, Europa y Japón.

El Economist Intelligence Unit calcula que el crecimiento económico de Latinoamérica será del 3,8 por ciento en el 2008 y del 4,2 por ciento para el 2009 , frente al 5,1 por ciento previsto para este año y al 5,3 por ciento registrado en el 2006. 


\section{Gilberto José Rafael Cárdenas Núñez}

No obstante, no cambia su previsión sobre la fuerte ralentización en la economía estadounidense para el último trimestre del año por el empeoramiento en el consumo privado debido a la crisis inmobiliaria.

El crecimiento en Estados Unidos seguirá afectado durante casi todo el 2008, añade el informe.

Según el informe, ese encarecimiento del crudo, que cotiza actualmente cerca de los cien dólares, se debe en parte a las continuas reducciones en las reservas sobre un trasfondo de continuo desequilibrio entre las tendencias de la demanda y la oferta."

Actualmente se ciernen sombras de una segunda gran crisis de la globalización a tan solo 10 años de la primera, cuyas características centrales son el dinamismo extraordinario de las economías asiáticas que presionan los mercados internacionales, provocando presiones inflacionarias por la cantidad demandada creciente de materias primas (incluyendo petróleo), de alimentos incluyendo trigo, maíz y soja, y de comodities, estos últimos son los que impactan directamente en el crecimiento de la economía peruana. Un segundo elemento condicionante de la segunda gran crisis de la globalización es la expansión extraordinaria de los valores secundarios generados por el mercado de valores hipotecarios en los Estados Unidos de Norteamérica, condicionados a su vez por la creciente abundancia del dólar en los mercados financieros como moneda débil, frente a las presiones del euro como moneda fuerte y de confrontaciones políticas que amenazan la capitalización del dólar como reserva internacional neta en muchos países.

\section{Cuadro $\mathrm{N}^{\circ} 2$}

Composición de las exportaciones Peruanas según país de destino

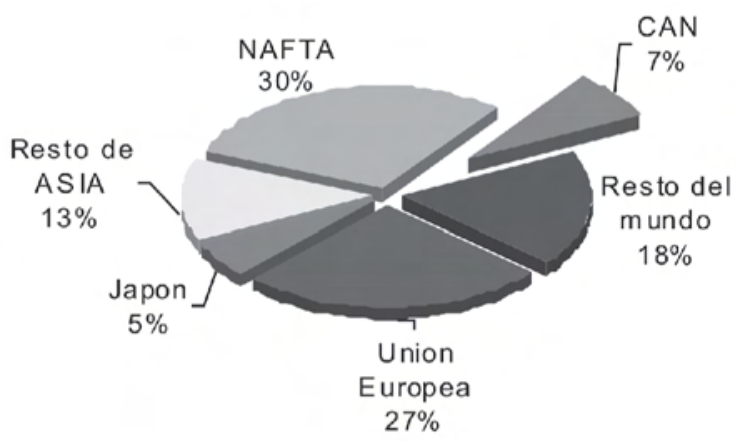


Como se puede apreciar en el grafico anterior los principales clientes comerciales internacionales del Perú son los Estados Unidos (incluido en el NAFTA ), China (incluido en el Resto de Asia), en Europa ( Suiza, Alemania e Inglaterra principalmente ) y Chile (incluido en Resto del Mundo). El impacto de la recesion Norteamericana previsible para el 2008 afectará necesariamente las exportaciones del Perú a este principal cliente internacional.

Otro condicionante consiste en el cambio tecnológico que genera nuevos hábitos de consumo de las poblaciones mundiales que participan en el mercado modificando los precios relativos y generando demandas sorprendentes de algunos materiales escasos o de nuevos materiales, como es el del antimonio en el caso peruano.

\section{3.-Tendencias de la evolución del PBI de la economía peruana}

El crecimiento de la economía peruana en el marco de los condicionantes, y a decir del propio ministro de economía y finanzas del Perú, se estima sostenido por lo menos hasta el año 2008. Esto quiere decir que el incremento del PBI se calcula en $8 \%$ para el año 2007 y $8 \%$ para el año 2008, que sin embargo, podría perder 2 puntos afectado por el impacto de la crisis inmobiliaria de los Estados Unidos.

\begin{tabular}{|c|c|c|c|c|}
\hline & 2005 & Isem - 06 & $2006 \mathrm{E}$ & $2007 \mathrm{P}$ \\
\hline $\begin{array}{l}\text { Agropecuario } \\
\text { Pesca }\end{array}$ & $\begin{array}{l}4.8 \\
1.2\end{array}$ & $\begin{array}{r}3.2 \\
-2.3\end{array}$ & $\begin{array}{r}3.3 \\
-0.9\end{array}$ & $\begin{array}{l}3.5 \\
4.5\end{array}$ \\
\hline M ineria e hidrocarburos & 8.1 & 6.6 & 2.0 & 5.9 \\
\hline $\begin{array}{l}\text { Manu factura } \\
\text { - D e proces am iento de recursos primarios }\end{array}$ & $\begin{array}{l}6.4 \\
4.5\end{array}$ & $\begin{array}{l}4.7 \\
1.5\end{array}$ & $\begin{array}{l}5.7 \\
1.8\end{array}$ & $\begin{array}{l}6.1 \\
3.5\end{array}$ \\
\hline $\begin{array}{l}\text { - No primaria } \\
\text { Construc ción }\end{array}$ & $\begin{array}{l}7.0 \\
8.4\end{array}$ & $\begin{array}{r}5.5 \\
14.8\end{array}$ & $\begin{array}{c}6.7 \\
13.7\end{array}$ & $\begin{array}{c}7.5 \\
10.0\end{array}$ \\
\hline $\begin{array}{l}\text { Com ercio } \\
\text { Otros servicios } 1 /\end{array}$ & $\begin{array}{l}5.2 \\
6.3\end{array}$ & $\begin{array}{l}8.7 \\
6.9\end{array}$ & $\begin{array}{l}8.0 \\
6.9\end{array}$ & $\begin{array}{l}5.8 \\
5.9\end{array}$ \\
\hline VALOR AGREGADO BRUTO (VAB) & 6.2 & 6.7 & 6.5 & 6.0 \\
\hline $\begin{array}{l}\text { Im puestos a los productos y derechos de } \\
\text { im portación }\end{array}$ & 8.5 & 5.5 & 7.7 & 0.8 \\
\hline PRO DUCTO BRUTO INTERNO & 6.4 & 6.6 & 6.6 & 5.5 \\
\hline$\checkmark A B$ de los sectores primarios & 5.8 & 3.9 & 2.6 & 3.9 \\
\hline$\checkmark A B$ de los sectores no primarios & 6.3 & 7.5 & 7.8 & 6.5 \\
\hline
\end{tabular}


Otras instituciones como el Instituto Peruano de Economía consideraron inicialmente un menor incremento del PBI para el 2007, para el 2008 y 2009, estimaciones muy bajas a la luz de los resultados que hasta Octubre del 2007 viene presentando la economía peruana. Para el 2007 se estima que el incremento del PBI superara el $8 \%$, pero las previsiones para el 2008 y años sucesivos serán necesariamente menores debido al impacto de la crisis immobiliaria norteamericana.

En consecuencia, es previsible también una tendencia a la baja en la cotización de los minerales debido a que difícilmente la creciente cantidad demandada de minerales por la economía China pueda suplir la disminución que provendría de la economía norteamericana.

En el cuadro siguiente podemos apreciar al sector construcción como el más dinámico de la economía peruana, consistente con las estimaciones del ministro Carranza aunque periodos diferentes, y esto se debe principalmente al impulso en la construcción de viviendas y en menor medida a infraestructura física productiva como es la construcción de carreteras, centrales hidroeléctricas y al condicionamiento urbano entre otros.

\section{Cuadro $N^{\circ} 4$ - Crecimiento del PBI}

(en variación \% anual)

\begin{tabular}{|c|c|c|c|c|c|}
\hline Sectores Eoonómicos & 2005 & 2006 & 2007 & 2008 & 2009 \\
\hline Agricultura & 4.8 & 5.6 & 30 & 4.1 & 42 \\
\hline Pesca & 1.2 & 0.6 & 4.9 & 7.6 & 6.5 \\
\hline Mineria e Hidrocarburas & 8.1 & 5.4 & 7.0 & 5.1 & 46 \\
\hline Manufactura & 6.5 & 4.4 & 38 & 6.2 & 5.5 \\
\hline Procesadores de recursos primarios & 2.1 & 1.8 & 1.5 & 4.8 & 30 \\
\hline Industria no prinaria & 7.7 & 7,0 & 6.0 & 6.5 & 6.2 \\
\hline Construcciön & 8.4 & 15,0 & 83 & 12.3 & 11,0 \\
\hline Comercio & 5.2 & 10.3 & 6.5 & 4.7 & 5.1 \\
\hline Servicics & 6.3 & 8.5 & 7.0 & 53 & 4.9 \\
\hline Valor Agrega do Pru bo IVAB & 6.2 & $7+7$ & 61 & 86 & 35 \\
\hline $\begin{array}{l}\text { Impuestos a las productos } y \text { derechos de } \\
\text { irmportacion }\end{array}$ & 8.5 & 5.3 & 4.4 & 4.0 & 40 \\
\hline PE Global & 6.4 & 7.5 & 6.0 & 5,5 & 52 \\
\hline VAB Prisiario & 5.4 & & & 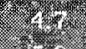 & \\
\hline VAB No Primario & 6.5 & & & & \\
\hline
\end{tabular}

Fuente: Instituto Peruano de Economia 


\section{¿El estado opuesto al crecimiento económico?}

El problema de la construcción de viviendas, principal política económica de los gobiernos de Toledo y del actual de García, es que tienen un efecto multiplicador "hacia atrás" lo que significa que el impacto de la construcción de la vivienda es muy fuerte en los sectores articulados en una relación insumo producto en especial con los insumos, en otras palabras en los proveedores de cemento, acero, ladrillo agregados, materiales eléctricos, sanitarios, pinturas, muebles y otros de madera y en otros en general, pero que una vez concluida la construcción de la vivienda su aporte productivo a la economía es mínimo. La diferencia de una política económica orientada a la construcción de infraestructura física como carreteras, centrales hidroeléctricas , puertos, redes de transmisión eléctricas, canales de riego, puertos, aeropuertos y otros, es que al concluirse esas obras se genera una nueva actividad productiva con empleo permanente (a diferencia de la construcción de viviendas que al concluirse cesa el empleo y no hay producción de nada), propiciando externalidades positivas con incremento sostenido del Producto Bruto Interno.

\section{4.- La gobernabilidad y la política económica}

Un condicionante interno es el nivel de gobernabilidad que tiene el Presidente de la República que se sustenta en una tendencia a menos del $30 \%$ de aprobación presidencial en octubre del 2007 (fuente: Apoyo, Opinión y Mercado). Apreciamos un deterioro significativo pues su aprobación disminuyó en $50 \%$ desde el inicio de su mandato.

Encuestas recientemente publicadas expresan que en el interior del País tanto en los departamentos de sierra como en la selva y, en general todos lo departamentos excepto Lima y Callao, muestra una creciente desaprobación del gobierno, y según un analista la tendencia podría ser mas a la baja : ${ }^{\mathrm{O}}$

"Al comentar el 69 \% de desaprobación que alcanzó el Presidente en el reciente sondeo de Datum, Sinesio López señaló que "era previsible, pues el gobierno no realiza 


\section{Gilberto José Rafael Cárdenas Núñez}

cambios sustantivos".

"El problema más grave agregó es que la población no siente los efectos del crecimiento económico y de una política social agresiva. La eficacia del Estado es escasa en el norte, centro y sur".

Dijo a este diario que de seguir la misma política gobiernista, la aprobación de García puede llegar hasta 8 o $10 \%$.

López abogó por una reforma tributaria de verdad, que cambie las políticas distributivas. "No es posible que el Estado lo financiemos todos y que solo sirva a los de arriba. Además hay falta de empleo y salarios bajos. El Perú sigue siendo último en calidad educativa", señaló".

\section{Cuadro $N^{\circ} 5$ - Aprobación presidencial de los primeros meses de gobierno}

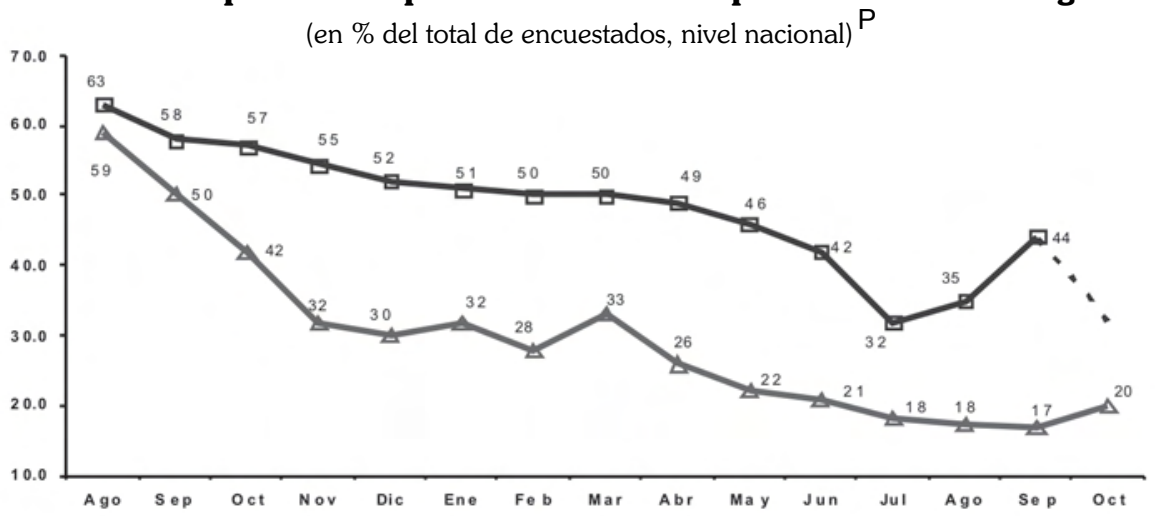

Un segundo elemento es la apreciación de la población en general sobre sus expectativas políticas: el APRA con 13 gobiernos regionales del 2002 2005, pasa a 3 gobiernos regionales para el periodo 2007 2010. En la práctica, la presencia gubernamental y las políticas económicas centrales tienen amplia recepción y colaboración en sólo el 10\% del territorio nacional, auque por incluir Lima impactan en el $40 \%$ de la población. En este sentido, la política minera por ejemplo, tiene el rechazo 


\section{¿El estado opuesto al crecimiento económico?}

creciente de la población del interior a pesar de los impactantes beneficios que genera la exportación de minerales y su consecuencia de recaudación tributaria. En "El Perro del Hortelano", el Presidente de la República cuestiona severamente la política de protección de medio ambiente, de muchas comunidades regionales, que lo hacen con razón, esto sin dejar de darle la razón al presidente en el sentido de que varios de los minerales que Perú exporta y que tienen elevados precios en el mercado mundial, ahora, por el cambio tecnológico necesariamente son insostenibles (cableado de cobre por cableado de fibra óptica, p. ej.) y que aconsejan explotar con premura parte de las vastas reservas de minerales sustituibles que posee Perú para generar un mayor beneficio en la economía peruana.

La distribución de la riqueza generada por el boom de exportaciones, y el incremento de la recaudación fiscal no es sentida por la población en los departamentos del país, y en lo que se refiere a Lima y Callao podemos apreciar en el cuadro siguiente que el nivel socioeconómico A ha incrementado notablemente sus ingresos, y en los estratos D y E la disminución de la pobreza pasa del $51 \%$ al $43 \%$, tendencia a la baja insuficiente pues significa que mas del $40 \%$ de la población nacional sigue siendo marginada económicamente y su participación en el mercado como consumidores es mínima, lo que significa que la población en situación de pobreza está al margen mayoritariamente de esta abundancia de dólares y de soles existentes actualmente en la economía peruana.

Se comprende entonces la creciente desaprobación presidencial lo cual va restando progresivamente capacidad de gobierno al Presidente de la República, de hecho como consecuencia de la carencia de un plan de gobierno, de la incapacidad de reformas institucionales y de la carencia de equipos profesionales altamente calificados en la gestión gubernamental.

En el cuadro siguiente se puede apreciar el impacto de 5 años de expansión del producto bruto interno peruano, que se estima al cierre del año 2007 en cien mil millones de dólares corrientes, y que suponen una mejora de la economía de todos los peruanos, pero cuyo impacto no necesariamente es democráticamente distribuido, y 


\section{Gilberto José Rafael Cárdenas Núñez}

que hacen necesario revisar la política económica general del gobierno en estos momentos.

Cabe indicar que los resultados de la redistribución no son iguales en las provincias de fuera de Lima y Callao.

\section{Cuadro No 6 - Gran Lima Distribución de los hogares por nivel socioeconómico, 2002 - 2006} (en \% del total de encuestados) $\mathrm{Q}$

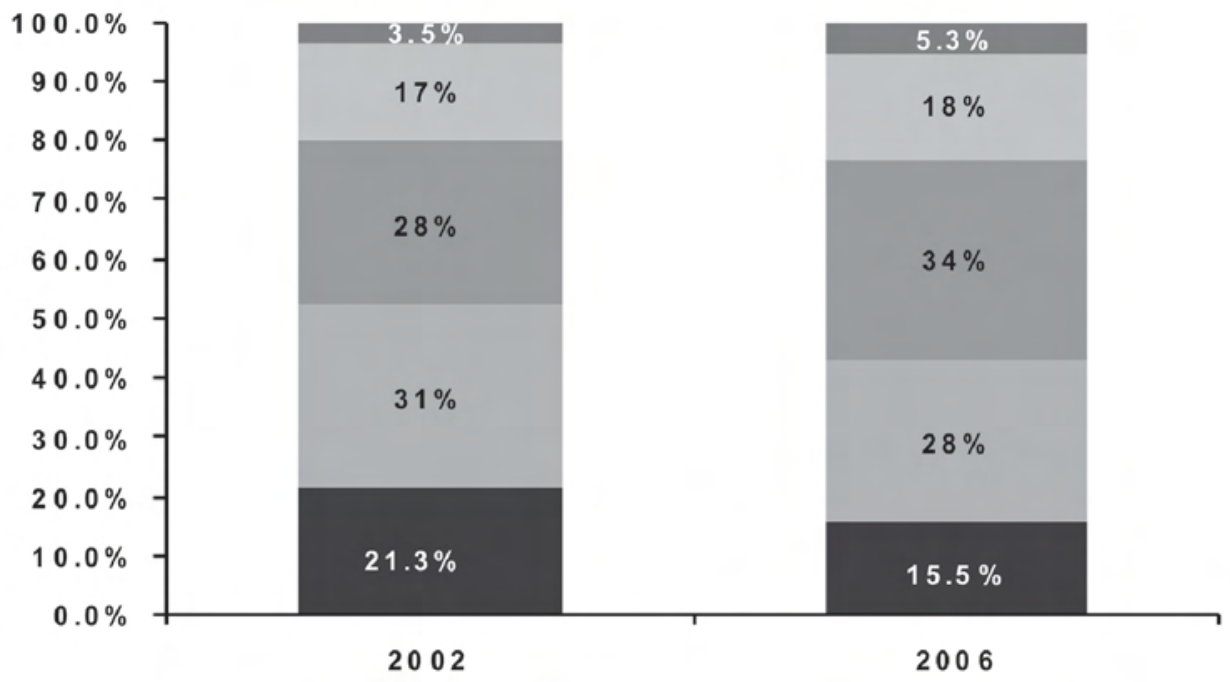

Otro condicionante es el enfoque de reducción del Estado, política construida a la luz de los planteamientos neoliberales de los gobiernos de Fujimori, Toledo y el actual de García, de un Estado como mal empresario y que no debe intervenir en la economía, que genera déficit fiscal y que debe apartarse de su acción empresarial e inversionista en la economía, elaborados e implementado inicialmente por Carlos Boloña cuando fue ministro de economía, y sustentados a través de normas de diferente carácter por los parlamentos del periodo de Fujimori y mayoritariamente en el periodo de Toledo. Estos criterios rigieron notablemente en la generación de los llamados "candados" (jerga parlamentaria que se refiere a restricciones a las libertades que da una norma). Candados, como el Sistema Nacional de la Inversión Pública que obliga a que toda 


\section{¿El estado opuesto al crecimiento económico?}

entidad del Estado tenga equipos profesionales de conocimiento universal (de todas las materias) para que puedan decidir qué proyecto está bien sustentado o no, sea del ámbito agrícola, pesquero, minero, manufacturero, eléctrico, de saneamiento, forestal, educativo o de salud por mencionar algunos, es claramente percibido que ninguna entidad pública puede tener un equipo de especialistas en todo, con los conocimientos avanzados (usualmente de post grado) que requiere la evaluación de un proyecto.

\section{6.- El centralismo continúa}

En el caso de los gobiernos regionales, es conocido el hecho que no tienen capacidad de gasto y que los fondos de canon y regalías están depositados en le Banco de la Nación sin haber sido ejecutados en los periodos 2005, 2006 y 2007, lo que significa que a pesar de existir crecientes demandas poblacionales y enormes necesidades no se esta haciendo la obra necesaria.

Significa también que en la mayoría de casos el impulso productivo de varios departamentos se ha realizado sin la contribución determinante de la inversión pública generando restricciones a la producción y severas limitaciones a la competitividad de la economía peruana.

En el cuadro siguiente se puede apreciar que los principales departamentos que se han visto beneficiado por el APTDEA son los que están ubicados en la costa del Perú, pues disponen de los puertos y carreteras a través de los cuales los productos salen al exterior; significa también el desarrollo productivo costero (agrícola y manufacturero), con la consiguiente generación de empleo permanente, mejora de los ingresos y aumento de la capacidad productiva respectiva.

Así podemos apreciar que el departamento mas dinámico es Ica a pesar del reciente sismo que afecto la zona. Luego sigue Iquitos, Piura y Chimbote, en la generación de empleo productivo, que representa pues la mayor inversión en los referidos lugares. 


\section{Gilberto José Rafael Cárdenas Núñez}

Los departamentos de la costa son ampliamente favorecidos por el ATPDEA, mientras que en el interior del país la globalización, el proceso de internacionalizacíon de la producción, las finanzas y la inversión no es mayormente notable.

\section{Cuadro $\mathbf{N}^{\circ} 7$}

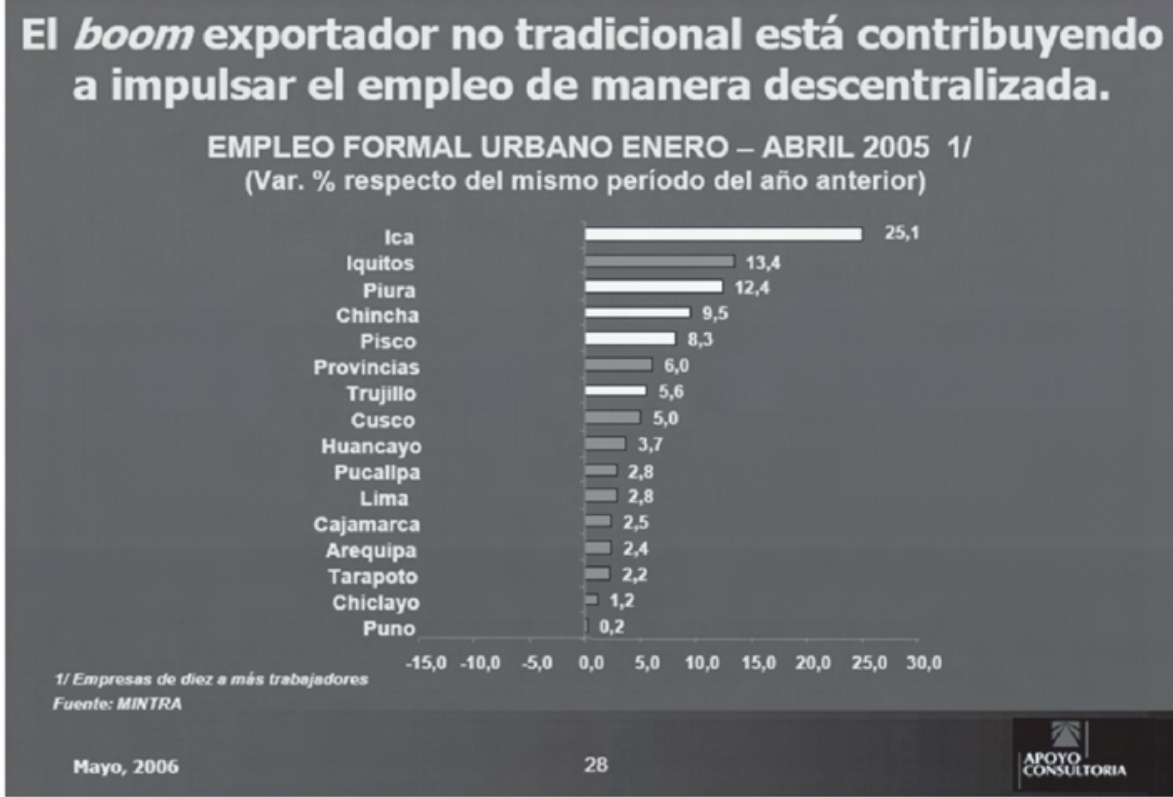

La carencia de empleo en los departamentos de la Sierra y Selva son el sustento de la desaprobación presidencial, puesto que la población conocedores del boom exportador, de los mayores ingresos fiscales y de la creciente capacidad adquisitiva de Lima principalmente, perciben que las distancias distributivas del ingreso y del empleo, así como de la competitividad y bienestar son mayores.

Migrar para vivir en Lima o en el Callao siguen siendo formas de mejorar las condiciones de vida, aún cuando se forme parte de los estratos de la pobreza y extrema pobreza de la capital. La pobreza es absoluta en el interior del País, mientras que en Lima existen, aún en la pobreza, mejores oportunidades de mejorar las condiciones de vida. 
¿El estado opuesto al crecimiento económico?

Cuadro $N^{\circ} 8$ - Gasto per capita promedio mensual por regiones, 2006

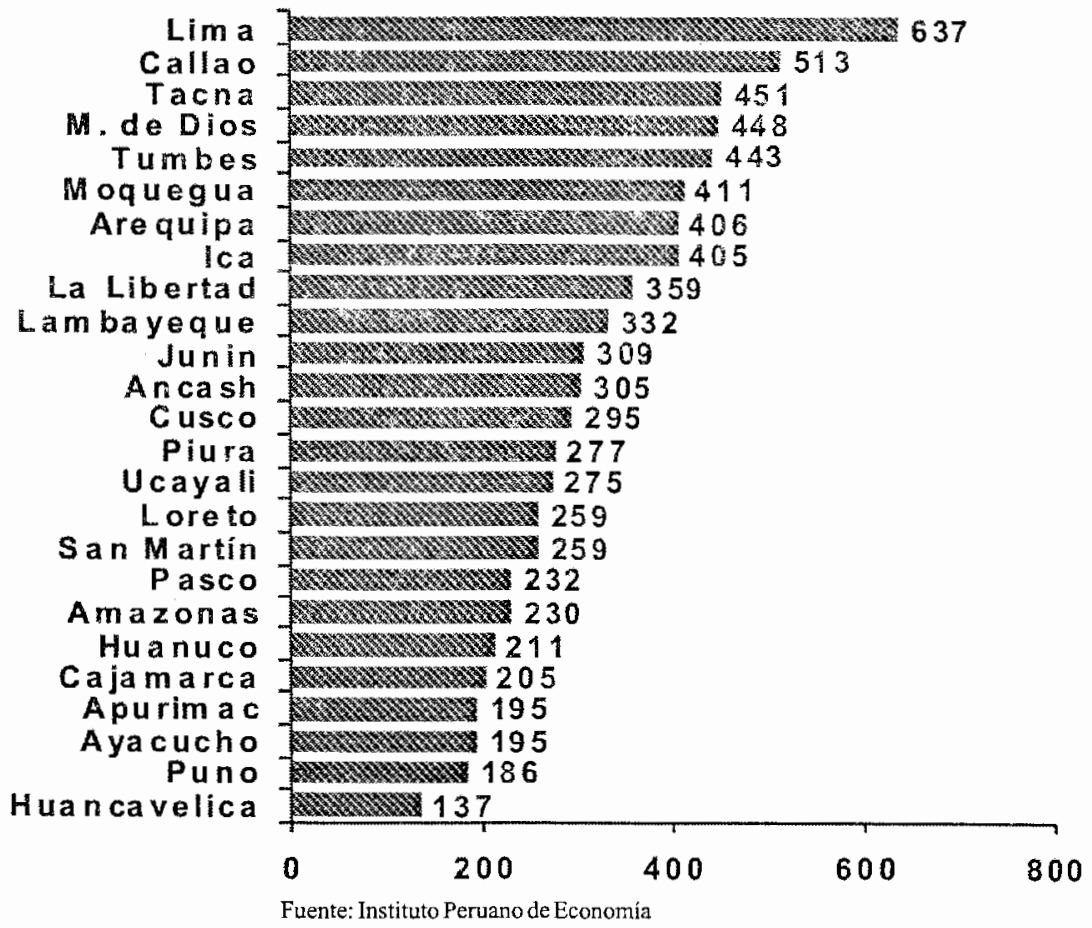

Como se puede apreciar la capacidad de Gasto (y en consecuencia de obtención de ingresos) está en Lima y Callao, relacionándose estrechamente con los mayores indicadores de aprobación presidencial en dichas zonas. También se puede apreciar que los diez primeros lugares (con excepción de Madre de Dios) son departamentos que tienen costa y que por lo tanto son los que se vinculan con el mercado internacional beneficiándose del ATPDEA, y en perspectiva con el Tratado de Libre Comercio con los Estados Unidos.

Otra observación importante es que el centralismo continúa (si es que no se agudiza), demostrando esto que las políticas de descentralización implementada por los gobiernos de Toledo y García son un fracaso al no desarrollar economías regionales dinámicas. 


\section{Gilberto José Rafael Cárdenas Núñez}

Pero además existen otros candados que han generado desde escándalos hasta burlas como es el procedimiento para las compras estatales. Desde la elaboración de las bases técnicas para la compra de escritorios, computadoras, vehículos, equipamiento de instituciones de salud, inmuebles u otros, estamos frente al mismo fenómeno que se percibe en el caso del SNIP: la necesidad de equipos multidisciplinarios de alta calificación, y que las instituciones públicas los tienen mínimamente, o en forma parcial, o mal remunerados. Las compras de patrulleros y ambulancias, de equipos y alimentos de emergencia para la zona de Ica y en general cualquier tipo de compra se encuentra con un proceso de muchos pasos a seguir, con ambigüedad en las normas, con normas hechas para evitar las corrupción y que complican el proceso y no evitan la corrupción y que dan como resultado un superávit fiscal exorbitante, que retrasa la necesaria construcción de infraestructura física e infraestructura institucional necesaria para la modernización del país acorde con el proceso de modernización contemporánea.

Un tercer candado de especial importancia es la consideración en el presupuesto público de un proyecto o una obra, su financiamiento una vez priorizado y la licitación para su ejecución además de la licitación o concurso para la supervisión de la ejecución de la obra. Significa esto, que el entrabe administrativo para la ejecución de obras es elefantiástico y muy pocos funcionarios se atreven a enfrentar el compromiso de seguir estas pautas, pues basta que se les olvide una para que estén sujetos a procesos administrativos civiles o penales. La infraestructura institucional no está desarrollada en el Perú, para un Estado que tiene abundantes recursos y que se puso a sí mismo limitaciones ajustadas con el argumento ideológico que en Estado no debe intervenir en la economía.

\section{Conclusiones}

El crecimiento económico encuentra limitaciones internas en la infraestructura física institucional, agravadas por la carencia de acciones de política económica que se oriente a una reestructuración de la política tributaria, a la creación de una política de 


\section{¿El estado opuesto al crecimiento económico?}

empleo efectiva, y a la constitución de un esquema de desarrollo productivo de largo plazo para el Perú, manifestándose esto en la ausencia de un plan estratégico nacional que coordine las acciones de los gobiernos regionales, los gobiernos locales y el gobierno central.

El Estado no tiene la capacidad en términos de recursos humanos para construir la infraestructura física e institucional, en parte debido a la que la estructura del Estado se ha desprofesionalizado, lo cual significa que los principales recursos humanos especializados formados en la décadas pasadas han sido despreciados y marginados por muchas entidades publicas, y como consecuencia la memoria histórica para plantear el desarrollo del país se está desperdiciando. A esto se suma una absoluta y caótica confusión y desorden en la política de remuneraciones que no promueve la carrera pública, elemento fundamental para el diseño supervisión y ejecución de proyectos e inversiones los cuales el Estado no ha podido ni puede ser reemplazado por el sector privado.

La política económica es errática por la carencia de un Plan Estratégico Nacional, significa que la gestión gubernamental y en muchos casos de los gobiernos regionales y municipales se centra en la búsqueda de "televisión" y no en la generación de infraestructura productiva, formación de recursos humanos calificados y construcción de infraestructura institucional que permita al Estado efectuar las inversiones necesarias para el crecimiento y desarrollo de la economía nacional . 


\section{BIBLIOGRAFÍA}

- Álvarez Rodrich, Augusto; "Empresas Estatales y Privatización", Editorial Apoyo, 1991, Perú..

- Campodónico Sánchez, Humberto; "Cristal de Mira 2002 - 2006", UNMSM, 2006, Lima Perú.

- Cárdenas Núñez, Gilberto José Rafael; "Reformas Estructurales: la Regionalización un Fracaso Calculado", Pensamiento Crítico No 4, 2005, Lima Perú.

- Griffith-Jones, Stephany; "Deuda Externa, Renegociación y Ajuste en América Latina", Fondo de Cultura Económica, 1998, México D.F.

- Hanke, Steve H., "Privatización y Desarrollo", Centro Internacional para el DesarrolloEconómico", 1991, Mexico D.F.

- Stiglitz, Joseph E.; "El Malestar en la Globalización”, Taurus, 2002, Buenos Aires, Argentina.

\section{Notas Referenciales}

1 Coyuntura-latinoamerica 23-11-2007Latinoamérica, región emergente más afectada por crisis EEUU, según Economist Latinoamérica será la región de mercados emergentes más afectada por la ralertización económica estadounidense y las peores condiciones de financiación, según un informe hecho público hoy por el Economist Intelligence Unit (EIU), división de análisis de la revista 'The Economist'.

2 La Republica 24 de Noviembre del 2007

3 Fuente:Apoyo Opinión y Mercado

4 Ob. Cit. 3 